\title{
Article \\ Stakeholders' Participation in Sustainable Tourism Planning for a Rural Region: Extremadura Case Study (Spain)
}

\author{
Marcelo Sánchez-Oro Sánchez ${ }^{1}$ (D) José Castro-Serrano ${ }^{2, *(\mathbb{D})}$ and Rafael Robina-Ramírez ${ }^{1}$ (D) \\ 1 Department of Business and Sociology, Universidad de Extremadura, 10071 Cáceres, Spain; \\ msanoro@unex.es (M.S.-O.S.); rrobina@unex.es (R.R.-R.) \\ 2 Department of Art and Land Sciences, Universidad de Extremadura, 10071 Cáceres, Spain \\ * Correspondence: josecastro@unex.es
}

check for updates

Citation: Sánchez-Oro Sánchez, M.; Castro-Serrano, J.; Robina-Ramírez, R. Stakeholders' Participation in Sustainable Tourism Planning for a Rural Region: Extremadura Case Study (Spain). Land 2021, 10, 553. https://doi.org/10.3390/land10060553

Academic Editor: Antonio Raschi

Received: 14 April 2021

Accepted: 20 May 2021

Published: 24 May 2021

Publisher's Note: MDPI stays neutral with regard to jurisdictional claims in published maps and institutional affiliations.

Copyright: (c) 2021 by the authors. Licensee MDPI, Basel, Switzerland. This article is an open access article distributed under the terms and conditions of the Creative Commons Attribution (CC BY) license (https:// creativecommons.org/licenses/by/ $4.0 /)$.

\begin{abstract}
The objective of this research is to obtain and analyze discursive information on the problems and solutions of the tourism sector in an eminently rural region, such as Extremadura, based on the opinions of stakeholders, in order to incorporate them into the evaluation and tourism planning of the region. More specifically, on the situation of the sector, perceptions on profitability and return on investment, the problem of overnight stays, and coordination between tourism agents and training demands, in order to make a sustainable tourism sector in a rural region. The research starts from the following premise: for tourism to be sustainable, stakeholders must participate in the strategic decision-making process. This paper aims, on the one hand, to clarify sufficiently the state of the art regarding the validity of focus groups and their analysis as a research methodology, explaining how to address the main challenges implied by this technique by reviewing a selection of research works that we consider relevant in this field. On the other hand, an analysis of the tourism sector in Extremadura is carried out based on these group dynamics. The main result, after analyzing the discourse of six focus groups, is that the different opinions of their members reveal, despite everything, that the training of human capital in the tourism sector in rural environments is a pending issue.
\end{abstract}

Keywords: focus groups; interest groups; stakeholders; tourism; Extremadura

\section{Introduction}

Focus groups, also known as "discussion groups" [1], spread to the field of social research, especially market research, in the 1950s. Until then, in the 1930s and 1940s, they had been used as a psychotherapeutic strategy. The work of R. Merton and M. Fiske, entitled The Focused Interview [2], is one of the first references in this field, and serves as a starting point for the use of these group dynamics in the sociological study of different problems [1].

Focus groups are currently considered the central practice of qualitative social research [3]. Their constitution is that of a small group, between five and nine people, in interaction, guided semi-directionally by a moderator. The dynamics, lasting about an hour and a half, are articulated as a device for interpersonal communication, for the production and analysis of the group's discourse. It is, therefore, a practice in more or less controlled conditions and subject to revision, and it is not a closed technique. Such a conversation, relatively spontaneous and open, is recorded and transcribed verbatim for sociological or socio-hermeneutic analysis [3]. It is important to consider that, depending on the participants in these sessions, what is sought is a certain confrontation of positions. Starting with minimal verbal stimuli, the moderator encourages discussion on a basic issue (mores, corporate images, products/brands, or, as in our case, local tourism policies). Discursive production may appear fragmentary, but it involves a coherent bundle of virtual discourses sometimes underlying them. Their systematization as elements of a symbolic universe aims at defining the social codification keys of dominant ideologies (or positions) [3]. In 
summary, focus groups are a qualitative research tool whose essential characteristic is the explicit use of group interaction to produce data and insights that would otherwise be less accessible [4,5]. It is, therefore, an artificially created relationship [6,7], which is based on the logic that only the consumer (the tourist) determines the meaning of a product or service [8]. In Weeden's opinion [6], focus groups, as a rich and valuable data collection method, can be excellent and provide the researcher with the perspective of a small segment of informants. They may reveal some issues that the researcher has not previously considered, such as the importance of critical timing in the configuration of opinions and future actions [6].

The methodology used in focus groups applied to the study of tourism has at least three implications. First, the approach goes beyond the reductionism of positivist (exclusively quantitative) methods, thus incorporating a holistic view of the tourism problem $[9,10]$. Second, the use of focus groups incorporates the results of the interaction between the researcher and the researched. Consequently, it is accepted that the interaction, elucidated from the assessment of the actors involved in tourism, influences changes in the perception of tourism-related phenomena [11,12]. Third, this highlights the convenience of adopting a methodologically eclectic position in tourism studies, integrating qualitative and quantitative aspects of research.

This means that researching the tourism phenomenon allows for the adoption of an adequate perspective for the development of inductive logic, which, as is known, starts with specific, concrete observations and builds general patterns so that the approach to the understanding of a social phenomenon is basically speculative and exploratory [13]. This is the logic underlying tourism research that uses focus groups as one of the basic tools for understanding the reality of tourism $[14,15]$.

Qualitative research focuses on observing people in habitual, everyday settings to understand and interpret how they maintain their social worlds. Hardy's [16] ontological assumption was that people, with their differences, perceive events in different ways [17,18]. Therefore, the goal is to understand how people perceive the world, the reasoning behind their actions, and to provide a deep understanding of social environments [15]. From this, the epistemological approach of this study assumes that values are inherent to human beings. Therefore, research cannot be value free. Research is subjective, as a result of the interaction between two people: the researcher and the respondent [17]. Consequently, it is assumed that perceptions of "reality", as understood by the respondent, would be formed by the researcher $[12,19]$.

As part of the methodological logic of qualitative research, the data provided by the focus groups are not intended to be statistically representative [7]. However, focus groups are an appropriate tool to discover the perceptions and perspectives on a wide variety of tourism-related aspects, as they provide a broad understanding of the way of thinking, beliefs, and attitudes of both tourists and the social actors involved in this sector of activity $[20,21]$.

This work is the result of research that uses focus groups to learn the perspective of stakeholders (agents or interested parties) in tourism. For this purpose, six group dynamics were carried out in different locations in Extremadura (Spain). The qualitative perspective adopted in this work consists of using an exploratory approach, focused on a small number of people and/or cases (although sufficiently significant), which are usually studied to determine the meaning of social problems generalizable to large populations, and for a genuine understanding of information [22-24].

We consider that the main contribution of this article is to gather significant references in the field of the study of tourism, based on qualitative techniques, such as focus groups, to analyze these references in order to try to find elements of connection and coherent articulation with a view to their application to the specific case of the evaluation of regional tourism policies, such as the study of the assessments and perceptions of tourism development held by stakeholders in a peripheral region of southern Europe. 
This article arises in a context in which political leaders and professionals in the tourism sector tend to take into account only quantitative data on tourism supply and demand when analyzing the situation of the sector. This work aims to highlight the fact that statistical analyses must be complemented by the discursive contribution, duly treated and processed, of significant leaders in the sector. Reflection on the local and regional tourism reality can be understood in a more complete way if the stakeholders' contributions are taken into consideration. The analysis and interpretation of the reality of tourism should not be limited exclusively to statistical and quantitative research but should be complemented by the analysis of the stakeholders' discourse through research methodologies and analysis by means of focus groups. With these group dynamics it is possible to involve the essential actors of the sector, improving the interpretation of the data and making possible a more realistic planning of future strategies for the development of the sector.

Table 1, based on a deductive approach, shows the stages of this process. SánchezHernández, Robina-Ramírez, and De Clercq [25] explain that the application of deductive categories works on the basis of a prior theoretical definition of the main aspects of the analysis, which connects them with the texts.

Table 1. Deductive model applied.

\begin{tabular}{|c|c|}
\hline Stages & \\
\hline (1) Objectives: Research Proposals & \\
\hline $\begin{array}{l}\text { (2) Definition based on theory: Main } \\
\text { categories-Subcategories }\end{array}$ & \\
\hline (3) Codebook & 3.1. Formative reliability check \\
\hline (4) Working through reports (code merging) & 4.1. Summative reliability check \\
\hline (5) Interpretation of the results & \\
\hline Discussion/Conclusions & \\
\hline
\end{tabular}

The collection of codes in a coding diary is the way to verify reliability (formative checking). Making categories and code definitions explicit is an important part of the analytical process, as elucidated by Bernard, H.R. and Ryan, G.W. [26]. Subsequently, the transcribed texts of the audio recordings of the focus groups are analyzed by assigning codes that, in turn, may generate new codes, which are to be merged, and if necessary, accepted and integrated into the coding agenda, being considered as another result of the research and an adaptation of previous theory to real case studies. According to SánchezHernández, Robina-Ramírez, and De Clercq [25], text coding could be interpreted as a "summative check" of reliability. Therefore, after the first round of work on the transcripts, we focused on the main categories and subcategories. Finally, we reached the point where a repetition of codes occurs and theoretical saturation is reached.

\section{Literature Review}

Focus groups, understood as individuals having a discussion on a delimited set of topics and expressing their attitudes and opinions interactively, have been widely used as a form of qualitative research analysis [15]. By using them, researchers can obtain a better idea of the design of pre-questions and conceptual explanations for a given target group of customers-tourists [27].

Pearce and Gretzel [28], in line with the work of Jacobsen [11], introduce into the qualitative perspective the emic-etic disjunctive. In their view, what underpins focus group studies is the emic approach, a perspective that is consistent with recent concerns in social science research about the relationship with the evaluation of human responses to social problems. As Rossite [29] suggests, researchers have been too preoccupied with the 
reliability of their instruments and testing the validity of their tools by statistical indices, such as Cronbach's alpha, thinking that their measures are, therefore, sound. In the world of psychometrics, this is an incorrect view, since the tools of such summary statistics only report on the internal consistency of what has been measured, but not on the fundamental validity of the phenomenon under study. The views of Rossiter [29], are similar to those of Gomm [30], Pisani [31], Flick [32], and other authors who are specialized in ensuring that a phenomenon is well understood from the way we collect information, and who are consistent with the use of an emic approach as a first step to exploring reactions to new topics, such as tourist experiences, in areas without internet coverage ("dead zone"). This is the focus of the work we will discuss, which is based on the qualitative perspective. Pearce and Gretzel's [28] working procedure consists of selecting components for a total of five focus groups to investigate the experiential dimensions of being in dead zones. As suggested by these authors, the literature provides evidence that exploratory work in the field of tourism is particularly consistent with this emic approach, in which the issues that are important to the participants are key to the research [33]. The emic approach prevents researchers from prejudging problems that directly affect participants, as researchers' impressions can be misleading and fail to capture all components of interest, when their use of scales and structured response measures is indiscriminate to new research problems [29].

Qualitative research involves using a series of carefully designed controls and strategies to maximize the value of the approach [34]. These components include paying careful attention to participant recruitment, facilitator consistency, and a well-organized procedure to ensure the quality of information to be obtained, as implemented by Pearce and Gretzel [28] in their work on the experience of tourists in technologically "dead" zones.

One of the main problems presented by qualitative research is that of data validity. Angen [35] suggests that, within interpretive research, validation is "a judgment of the trustworthiness of an investigation". Qualitative research is often criticized for losing the principles of "good science". There are two reasons for this: positivism remains the predominant paradigm in many areas of tourism research. On the other hand, qualitative researchers often fail to explain the soundness of their methods. This leads to confusion and misunderstandings. Decrop [36] lists the basic criteria for assessing the reliability of a qualitative study, and proposes triangulation as a way to implement them. Triangulation consists of strengthening qualitative findings by showing that several independent sources converge on them, or at least do not oppose them. Decrop [36] describes and illustrates, with examples from tourism, Denzin and Lincoln's [37] four basic types of triangulation: data triangulation, method triangulation, researcher triangulation, and theoretical triangulation.

Another way to validate the data obtained through focus groups is detailed description through a precise documentation of the field of study. This is the case of Zhang Qiu S. et al. [13], who describe, in detail, the experiences, setting, and personal characteristics of the fieldwork, so that readers can determine whether the findings can be transferred to other settings due to shared characteristics [24].

All of the above has led some authors to speak of a "New Tourism Research". Tribe [38] justifies this expression in a series of works that explore, from different perspectives, the territory of tourism research. Tribe draws a line between research that is mainly confirmatory and reproductive, and that which seeks to re-conceptualize. The aim is to highlight new ways of looking at the tourism phenomenon, based on a wide range of studies that go beyond the narrow limits of applied business marketing. For this author, this is a sign of the growing maturity of research in this field. According to Tribe, a growing body of authors is adopting a reflexive stance following the example of Botterill [39], for whom reflexivity means looking and reflecting on themselves as researchers, and outwardly on those they "research".

Stakeholder participation in tourism planning and development can take place in a variety of ways: public hearings, advisory committees, surveys, focus groups, public 
deliberation, citizen review panels, civic review boards, working groups, implementation studies, and written comments. In any case, what is clear is that stakeholders must be part of the tourism planning and evaluation process [40-42].

The review of previous works has already shown that focus groups are a good tool for activating stakeholders, in order to explore the relationship between stakeholders and perceptions of change induced by tourism, in the context of sustainability objectives of the tourism business, as in the case of Hardy [16]. At the methodological level, Guba [17] considers two aspects: hermeneutics, where individual constructs are represented as accurately as possible; and dialectics, where constructs are compared and contrasted.

In essence, it is interesting to note that the information obtained by Hardy [16] through these qualitative strategies is classified into 14 types, which are grouped into four thematic axes: (1) the tourism product, (2) impacts, (3) planning for the present and future, and (4) the ghost community. In a way, these four dimensions correspond to the thematic axes considered by Carter [43], including what he describes as the "ghost population" (which we could assimilate to the floating population of many villages in Extremadura); the tourist guests and tourism organizations (tourism activity and planning for the present and future); and the nature environment (impacts).

Tourist needs are changing and competition between destinations is growing. Tourism participation, innovative partnership, and the relationship between guests and hosts is essential, and this is possible by implementing these group dynamics with stakeholders to identify attitudes, values, and feelings, in the development of the tourism destination, as proposed by Lindroth, Ritalahti, and Soisalon [21]. These researchers, as a sampling method, opted for the "snowball" technique, albeit introducing some biases in the selection of participants. For example, the moderators chose to exclude active stakeholders and involve artists, for example. The reason for these variations in the selection of participants was the need to listen to new voices and ideas indirectly involved in tourism, and to avoid having conflicts between public and private sector representatives. Lindroth, Ritalahti, and Soisalon [21] conducted five focus groups between March and June 2006. The number of participants ranged from five to twenty components. The sessions lasted two to three hours and were recorded and transcribed. The data were analyzed using constant comparative analysis, which can be considered as a general approach in qualitative analytical strategies, originally developed for use in Glaser and Strauss' "grounded theory methodology" [44]. In this case, the main results of the focus group discussions were the socio-physical environment of the destination, service structure, consumer behavior, information and communication technologies, traffic, logistics and accessibility, networks, tourism demand and supply, local resources, and marketing and public relations.

In conclusion, we can say that focus groups can be especially useful to verify tentative considerations, as shown by Morgan [45]. Zhang Qiu Set et al. [13] use these dynamics to promote the expression of the participants' points of view, creating a suitable environment to encourage discussion and different opinions and points of view. The researchers identify trends in the perceptions and opinions expressed through systematic analysis as pointed out by Gutiérrez Brito [7] and Krueger, R.A. and Casey, M.A. [46]. In this work by Zhang Qiu Set et al. [13], all the qualitative data (the discourse expressed by the focus group participants) were processed in the NVIVO tool, which allows us to qualify and clean the data, and to highlight significant statements, sentences, or quotations. Open coding is performed first to identify factors related to the study. The team of Zhang Qiu Set et al. [13] took special interest in the triangulation and validation of the data provided by the focus groups. In this study, a variety of methodological combinations (participant observation, interviews, document analysis and focus groups) were used for this purpose.

\section{Materials and Methods}

Based on the preceding explanations of the state of the question, this section identifies the research proposals, their meaning, and the authors who support them. Additionally, an 
analytical tree is constructed, which denotes the relationship between themes, categories, and subcategories.

\subsection{Methodology and Study Area}

In this paper, we used discourse analysis applied to six focus groups formed by stakeholders of the tourism sector in Extremadura, using the discourse analysis software ATLAS.ti. This analysis is based on qualitative research, since focus groups have been used as a means to study the role and opinions of stakeholders when it comes to planning and evaluating the sustainability of tourism in an area or region, as Hardy and Pearson have already shown [16].

The process of working with "ATLAS.ti" consists, basically, in classifying each sentence uttered by the participants in the focus groups with a "label" or "key word". This classification system is used to simulate the quantification of the discourse.

The research starts from the following premise: for tourism to be sustainable, stakeholders must be involved in the strategic decision-making process. However, who are the real stakeholders in tourism development? Additionally, how should planners and developers involve these stakeholders in the tourism development process in a given area? Erick T. Byrd [47] asserts that, in the definitions used for sustainability and sustainable tourism, four types of stakeholders are identified: current visitors, future visitors, the current host community, and the future host community.

The following research work focuses on the opinions of tourism stakeholders in Extremadura. For this purpose, six group dynamics were organized in different urban/rural centers of the region. Extremadura (see Figure 1) is a region of just over 1.1 million inhabitants, representing $2.3 \%$ of the population of Spain, with a population density of 26.4 inhabitants $/ \mathrm{km}^{2}$. The low weight of the population of Extremadura in the national total of Spain and its weak occupation of the territory are the essential characteristics of the demographic structure. According to the Statistics Unit of the Directorate General of Tourism of the Government of Extremadura [48], 1,866,168 travelers visited the region in 2018. More than $80 \%$ of these visitors to Extremadura were of national origin (Spanish), and the remaining $17 \%$ were foreigners. Together, they accounted for $1.43 \%$ of tourists from Spain. In terms of the number of travelers it receives, Extremadura ranks 14th in the ranking of the 17 autonomous regions.

The objective of the focus group research is to obtain discursive information on the problems and solutions of the regional tourism sector [7] from stakeholders in order to incorporate them into the evaluation and tourism planning of the region.

More specifically, the aim is to capture the "discourse" of stakeholders on the situation of the sector, perceptions on the profitability and return on investments made in the sector, the problem of the increase in overnight stays, the coordination of tourism agents, and the demands for training [16].

In order to investigate the concrete formulation of evaluations and proposals for solutions that stakeholders propose for the tourism sector in the region, we have started from the formulation of questions to be discussed in propositional methodological terms, based on the literature presented briefly in the previous sections [25]. Table 1 shows the deductive model applied for data analysis. The stages that referred to the "reliability check" (3.1 and 4.1) are presented in a very synthetic form in the "discussion" section, in order to avoid digressions parallel to the central line of this work. This reliability check, in essence, is based on the triangulation proposals of Zhang Qiu et al. [13], Creswell [24], and Patton [23], which, in our case, are semi-directive surveys for entrepreneurs and tourism managers, and are standardized surveys to a broad sample (6106 surveys) to tourists-both of which were carried out in the same period as the focus groups developed in this paper; that is, in the last semester of 2018 [49].

The following are the research propositions that guide this inquiry into the discursive expressions of the six focus groups. 


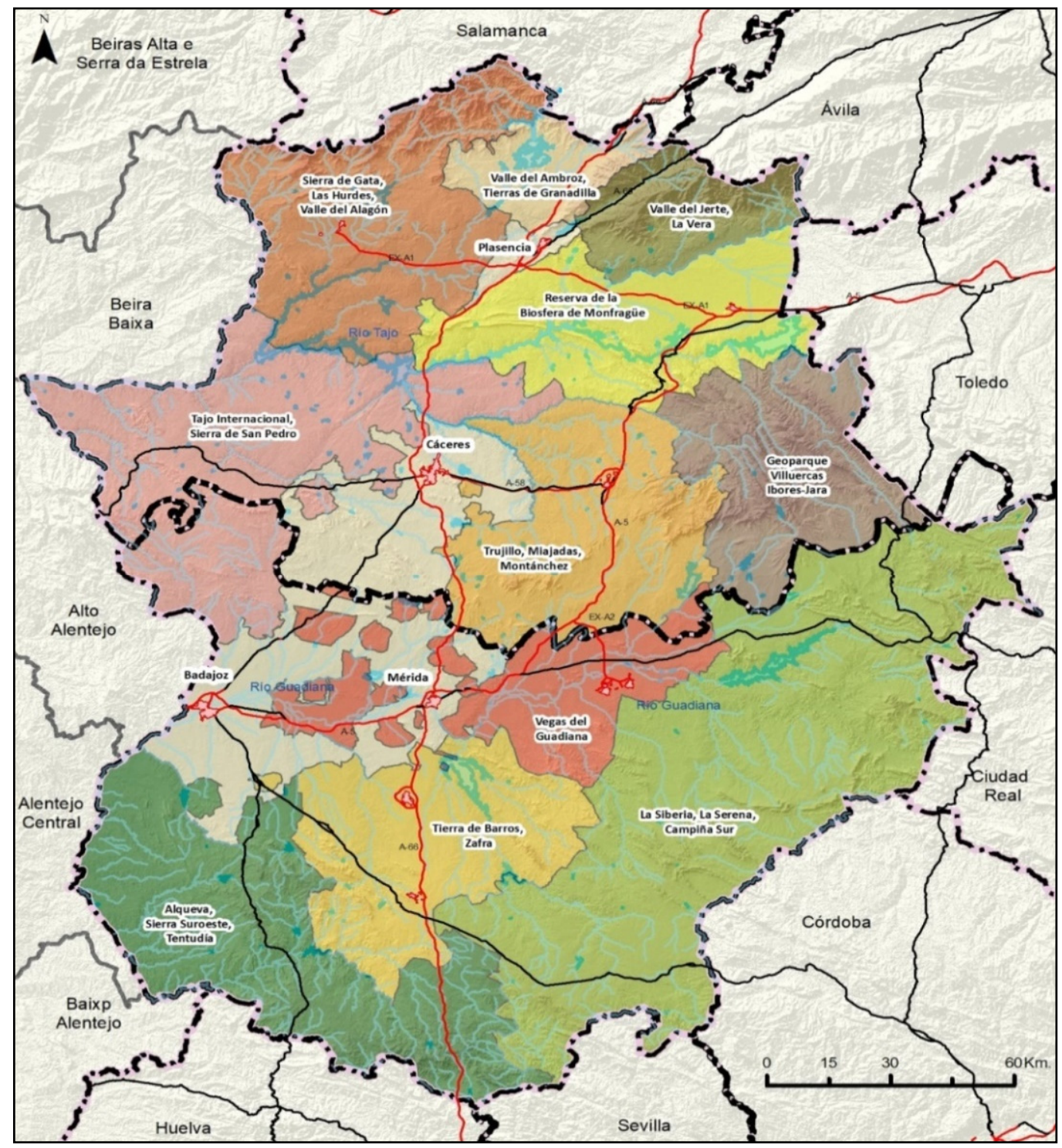

Figure 1. Tourist areas of Extremadura (Spain). Source: Tourism Observatory of Extremadura, Quarterly bulletin of tourism supply and demand in Extremadura Fourth-Quarter 2018 Document (14/2018). p. 78. https: / /www.viajarporextremadura. com/cubic/ap/cubic.php/doc/Guia-de-Extremadura-11.htm, accessed on 10 April 2021.

\subsection{Research Proposals}

In qualitative research, research problems can be posed in the form of propositions and questions to guide the inquiry. As King, Keohane, and Verba [50] point out that, ideally, all qualitative social science research projects should meet two conditions. Firstly, the research should ask questions that are relevant to the real world. Secondly, the research should contribute something concrete, "enhancing the collective capacity to provide scientific explanations for some aspect of the world" [50]. Our criteria for formulating the following research proposals explicitly mean that our work is situated within the framework of the existing scientific literature.

Proposition 1. Current situation of tourism in Extremadura. What are the stakeholders' perceptions of the evolution of the sector in terms of economic growth and social transformation? This evaluation of the sector includes the state of institutional relations between agents involved in tourism (Tribe [38]; Hardy [16]; Wilson, Fesenmaier, Fesenm, and Van Es [51]; González-Herrera and Álvarez-Hernández [52]). 
Proposition 2. Profitability and employment. Among the results required of the tourism sector in a region with high levels of unemployment, the need for tourism policies to have a social return that has an impact on tourism companies and employment stands out [16]. In this section, the aim is to collect contributions regarding opinions on institutional support for the sector and how the tourism labor market is perceived, a priori, characterized by job insecurity and low qualification of both employees and employers (Wilson, Fesenmaier, Fesenm, and Van Es [51]).

Proposition 3. The evolution of the tourism business is evaluated on the basis of "bookings, sales, and prices". How is this evolution perceived? What aspects favor or hinder inter-institutional coordination? How does this affect the tourism business? (Hardy [16]; Lindroth, Ritalahti, and Soisalon [21]).

Proposition 4. Typology of tourism. In such an extensive and diverse region, there are specific types of tourism (agritourism, events, cultural and historical tourism, and nature tourism) that need to be promoted in the different tourist areas, while other areas need to regulate their carrying capacity in order to make tourism activity sustainable without generating rejection among the population (Strielkowski, Riganti, and Wang [15]; Jacobsen [11]).

Proposition 5. Overnight stays. The increase in overnight stays is an essential indicator for the profitability of tourism investments and, to a certain extent, a legitimizer of public intervention in this sector. What can be done to increase the number of overnight stays by tourists visiting the region? (Hardy [16]; Wilson, Fesenmaier, Fesenm, and Van Es [51]; Lindroth, Ritalahti, and Soisalon [21]; Martinez Quintana and Blanco Gregory [53]).

Proposition 6. The role of tourism stakeholders (interest groups, administration, tourism professionals) is relevant for the evolution of the tourism sector; cooperation among them has an impact on the positive image of the sector and the region. In addition, it allows them to obtain a strong negotiating position vis-à-vis other authorities and sectors, with a view to future regulations and resource allocation (González-Herrera and Álvarez-Hernández [52]; Strielkowski, Riganti, and Wang [15]; Behringer, Buerki and Fuhrer [54]; Buhalis and Michopoulou [55]).

Proposition 7. Tourism promotion is a growing demand in the sector due to the increasing competition from other inland tourism markets. What ideas can be implemented to improve this promotion and support for it? (González-Herrera and Álvarez-Hernández [52]; Buhalis and Michopoulou [55]; Martínez Quintana and Blanco Gregory [53]).

Proposition 8. Specific training in tourism is one of the region's main challenges. It is considered that this factor can determine the evolution of the sector in two ways: in the improvement of supply and in the image of the jobs it generates, traditionally associated with precariousness and low salaries. Training goes hand in hand with training for entrepreneurship in the field of tourism (Wilson, Fesenmaier, Fesenm, and Van Es [51]; Behringer, Buerki and Fuhrer [54]; Hughes [56]).

The result of these propositions-questions is a large number of individual codes that we have grouped into analysis categories for processing in the ATLAS.ti tool, which evidently maintain associations among themselves. Figure 4 shows the final coding "agenda" developed for this study, which seeks, following Sánchez-Hernández, Robina-Ramírez, and De Clercq [25], to ensure both formative and summative verification of reliability (Figure 1). The interpretation of the results is presented in the form of concept maps (Figure 4). Cáceres' focus group makes possible the presentation of the research results and is the basis for the discussion and conclusions of our work (Santana Leitner [57], p. 135).

\section{Research Implementation}

The focus groups used as a basis for this research were formed following the criteria of heterogeneity and saturation proposed by authors such as Gutiérrez Brito [7] and 
Ortí [1]. Territorially, they were carried out in localities of the region, belonging to the urban (Cáceres, Mérida, Plasencia, Badajoz) and rural areas (Zafra and Guadalupe).

The discourse collected as a result of the focus group dynamics is part of and complementary to the contribution made by businesspeople and technicians through semi-directive interviews and standardized surveys (Sánchez-Oro Sánchez, Nieto Masot, Fernández Portillo, García García, and Cárdenas Alonso [49]).

The fieldwork was conducted from 17 to 30 October 2018, and the participants were relevant informants from the business sector and tourism technicians at the local and regional level, which we can typify as stakeholders (environmental and consumer associations, academics/scientists, entrepreneurs, managers of the chamber of commerce and industry, tourism business association, and trade unions) (Erick T. Byrd [47]; González-Herrera and Álvarez-Hernández [52]).

Speech processing was carried out with ATLAS.ti. Table 2 identifies the numbers of people summoned and those who actually attended the six sessions. The non-attendance rate (convened vs. actual attendees) is $45 \%$, in line with works, such as those by Behringer, Buerki, and Fuhrer [54], Taylor and Prideaux [58,59], and other similar works.

Table 2. Persons invited and attending the focus groups in Extremadura.

\begin{tabular}{lccccc}
\hline & Invited & Attending & Entrepreneurs & Technicians & Duration \\
\hline FG_CÁCERES & 14 & 9 & 4 & 5 & $130^{\prime}$ \\
\hline FG_MÉRIDA & 14 & 5 & 1 & 4 & $85^{\prime}$ \\
\hline FG_PLASENCIA & 14 & 7 & 3 & 4 & $115^{\prime}$ \\
\hline FG_BADAJOZ & 14 & 6 & 1 & 5 & $120^{\prime}$ \\
\hline FG_ZAFRA & 14 & 6 & 4 & 2 & $120^{\prime}$ \\
\hline FG_GUADALUPE & 14 & 5 & 2 & 3 & $80^{\prime}$ \\
\hline \multicolumn{1}{c}{ Total } & 84 & 38 & 15 & 23 & \\
\hline
\end{tabular}

Source: own elaboration.

In essence, the problems dealt with in the focus groups revolved around the thematic axes described in the code table (Table 3), which are the situations of the sectors. Although the moderator starts from the assessment of the situation in Extremadura, the groups quickly descend to their more concrete and daily reality: profitability and employment; reservations and sales; the types of tourism according to the greater or lesser impact they have on their territories; entrepreneurship in tourism; the return on investments made in the sector; the problem of how to increase overnight stays; the coordination of tourism policies; as well as whether the private actor is involved in the design of public policies and the training of tourism professionals. Figure 2 shows the weight, in absolute values, of each discussion axis, based on the mentions made by the groups as a whole. Table 4, on the other hand, presents the data according to each specific group.

Table 3. Categories and codes. Reference authors of the research propositions.

\begin{tabular}{|c|c|c|}
\hline $\begin{array}{l}\text { Categories and Codes of } \\
\text { Propositions } 1\end{array}$ & Definition & Authors \\
\hline \multicolumn{3}{|c|}{ Proposition 1. Current situation of tourism in Extremadura } \\
\hline 1.1. Higher growth & $\begin{array}{l}\text { General economic outlook for the sector in } \\
\text { relation to economic growth. }\end{array}$ & \multirow{2}{*}{$\begin{array}{l}\text { Tribe [38], Hardy [16], Wilson, } \\
\text { Fesenmaier, Fesenm, and Van Es [51], } \\
\text { González-Herrera and } \\
\text { Álvarez-Hernández [52] }\end{array}$} \\
\hline $\begin{array}{l}\text { 1.2. Coordination and } \\
\text { institutional support }\end{array}$ & $\begin{array}{l}\text { Assessment of institutional relations between } \\
\text { companies and the administration, according } \\
\text { to each tourist area. }\end{array}$ & \\
\hline
\end{tabular}


Table 3. Cont.

Categories and Codes of
Propositions 1

\begin{tabular}{llll}
\hline 2.1. Employment status & $\begin{array}{l}\text { Referred to the working conditions of } \\
\text { employees, which include, in general, deficient Hardy [16] } \\
\text { qualifications. }\end{array}$ \\
\hline 2.2. Institutional support & $\begin{array}{l}\text { Referred to the sources of financing and } \\
\text { subsidies for business initiatives within this }\end{array}$ & Wilson, Fesenmaier, Fesenm, and Van \\
tourism sector.
\end{tabular}

\section{Proposition 3. Evolution of the tourism business}

\begin{tabular}{|c|c|c|}
\hline 3.1. Bookings, sales, and prices & $\begin{array}{l}\text { Stakeholders' perception of profitability in } \\
\text { terms of "bookings, sales, and prices". }\end{array}$ & \multirow{3}{*}{$\begin{array}{l}\text { Hardy [16], Lindroth, Ritalahti, and } \\
\text { Soisalon [21], Aichholzer [58] }\end{array}$} \\
\hline 3.2. Return on investment & Return on investments made in the sector & \\
\hline 3.3. Companies & $\begin{array}{l}\text { Creation of companies and entrepreneurship } \\
\text { initiatives in the tourism sector. }\end{array}$ & \\
\hline
\end{tabular}

\section{Proposition 4. Typology of tourism}

4.1. Types to be enhanced

In certain tourist areas, there are types of tourism that should be promoted

Strielkowski, Riganti, and Wang [15] (Agrotourism, Hunting, Astrotourism etc.).

4.2. Types to be regulated There are areas that show high levels of tourist saturation that can cause rejection by the population.

Jacobsen [11]

\section{Proposition 5. Overnight stays}

5.1. Increase in overnight stays

It is understood that an increase in overnight stays is an indicator of a favorable evolution of the tourism business.

It is understood that a decrease in overnight

5.1. Overnight stays down stays is an indicator of an unfavorable evolution of the tourism business.

Hardy [16], Wilson, Fesenmaier, Fesenm, and Van Es [51], Lindroth, Ritalahti, and Soisalon [21], Martinez Quintana and Blanco Gregory [53]

\section{Proposition 6. The role of tourism stakeholders}

6.1. Integrated and coordinated sector

6.2. Disintegrated and competing sector
Generates solid negotiating positions in future regulations and resource allocation. Promotes a good brand and regional reputation.
Strielkowski, Riganti, and Wang [15], González-Herrera and

Álvarez-Hernández [52], Behringer,

Buerki and Fuhrer [54]

Buhalis and Michopoulou [55]

\section{Proposition 7. Tourism promotion}

7.1. The role of institutions and the role of companies

\subsection{The problem of communications} (train and airplane)

\section{Proposition 8. Specific training}

8.1. Improving qualification

\subsection{Entrepreneurship}

Weakens negotiating positions in future regulations and resource allocation. General reputational damage to the brand and the region.
The positioning of the region in a complex market requires investments in promotion. Investment in promotion may be conditioned by infrastructure problems that make the destination attractive but inaccessible.
González-Herrera and

Álvarez-Hernández [52]

Buhalis and Michopoulou [55],

Martinez Quintana and

Blanco Gregory [53]
Specific training that has an impact on the quality of services rendered.

Training for tourism entrepreneurship.
Behringer, Buerki and Fuhrer [54], Hughes [56]

Wilson, Fesenmaier, Fesenm and Van Es [51]

Source: own elaboration, based on Sánchez-Hernández, Robina-Ramírez and De Clercq. [25]. ${ }^{1}$ These synthetic "power ideas" can also be referred to as "labels", which are common in Atlas.ti text processing. 


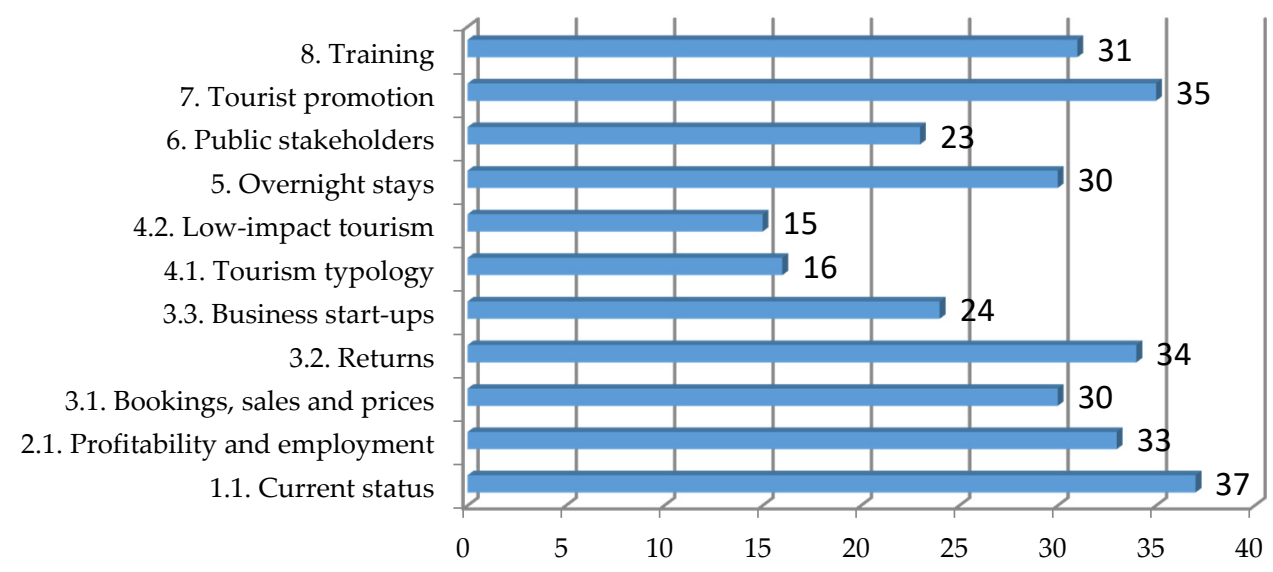

Figure 2. Discursive axes of all focus groups (absolute values: number of mentions). Source: own elaboration.

Table 4. Discursive axes (mentions) of the specific focus groups (absolute values).

\begin{tabular}{|c|c|c|c|c|c|c|c|}
\hline & BADAJOZ & CÁCERES & MÉRIDA & ZAFRA & PLASENCIA & GUADALUPE & Total \\
\hline \multicolumn{8}{|c|}{ Discursive axes } \\
\hline 1.1. Current status & 7 & 7 & 7 & 6 & 5 & 5 & 37 \\
\hline 2.1. Profitability and employment & 6 & 7 & 5 & 6 & 5 & 4 & 33 \\
\hline 3.1. Bookings, sales, and prices & 7 & 6 & 5 & 5 & 4 & 3 & 30 \\
\hline 3.2. Returns & 7 & 6 & 7 & 5 & 4 & 5 & 34 \\
\hline 3.3. Business start-ups & 3 & 6 & 4 & 4 & 3 & 4 & 24 \\
\hline 4.1. Tourism typology & 3 & 3 & 3 & 2 & 3 & 2 & 16 \\
\hline 4.2. Low-impact tourism & 3 & 3 & 3 & 2 & 2 & 2 & 15 \\
\hline 5. Overnight stays & 6 & 6 & 7 & 4 & 4 & 3 & 30 \\
\hline 6. Public stakeholders & 4 & 6 & 5 & 3 & 3 & 2 & 23 \\
\hline 7. Tourist promotion & 7 & 6 & 7 & 6 & 5 & 4 & 35 \\
\hline 8. Training & 6 & 6 & 6 & 4 & 5 & 4 & 31 \\
\hline Total references per FG & 59 & 62 & 59 & 47 & 43 & 38 & 308 \\
\hline \multicolumn{8}{|c|}{ Participants/time } \\
\hline Number of participants in each FG & 6 & 9 & 5 & 6 & 7 & 5 & 38 \\
\hline Time in minutes of each FG & $120^{\prime}$ & $130^{\prime}$ & $85^{\prime}$ & $120^{\prime}$ & $115^{\prime}$ & $80^{\prime}$ & $650^{\prime}$ \\
\hline
\end{tabular}

On the other hand, we made an approximation of the productivity of these groups. The development of the six focus groups involved a total of $10 \mathrm{~h}$ and $80 \mathrm{~min}$ of discourse on tourism in Extremadura by the stakeholders.

A correlation analysis [60] allows us to evaluate the performance of the groups (Table 5). In global terms, the relationship between the number of participants, the number of mentions, and the duration of the sessions shows that the longer the sessions last, the more productive the group is (correlation 0.95). While the number of participants has less of an effect on productivity, the correlation is low (0.49). As for the production of the specific groups, Table 5 shows that the Zafra group (0.94) has the highest correlation between the number of contributions made (mentions) and the total contributions made by all the groups; we could say that it is the "most productive" group. This is followed by Badajoz and Plasencia. It should be noted that the productivity of a group, in terms 
of the amount of discourse it is able to generate, also has much to do with the skills of the moderator of the sessions, and even the time of day at which a session is held and the location of the session; aspects that we have not evaluated in this study [12].

Table 5. Focus group performance indicators.

\begin{tabular}{cc}
\hline & Correlation \\
\hline GLOBAL PERFORMANCE INDICATORS \\
\hline Time/total references (mentions) & 0.95 \\
\hline Number of participants/time & 0.79 \\
\hline Number of participants/mentions & 0.49 \\
\hline PERFORMANCE INDICATORS BY FG, \\
\hline According to the number of mentions they produce, in relation to the total. \\
\hline ZAFRA & 0.94 \\
\hline BADAJOZ & 0.92 \\
\hline PLASENCIA & 0.91 \\
\hline MÉRIDA & 0.89 \\
\hline CÁCERES & 0.87 \\
\hline GUADALUPE & 0.84 \\
\hline
\end{tabular}

Source: own elaboration.

Finally, we would like to explain that certain aspects that were to be dealt with in the groups and that were fixed in advance by the researchers, were not dealt with specifically by the participants (we refer to items 1.2 and 2.2 in Table 2). In the cases of those referring to propositions $5,6,7$, and 8 , which we have broken down into several sub-categories in Table 2, they were treated jointly by many of the participants in the groups, so we will refer to them with a single digit.

\section{Results}

\section{General Discourse Analysis}

The first approach to the analysis of the discourse of the focus groups has been carried out by means of a "tree of relationships", which hierarchically integrates each of the sets of ideas and opinions expressed (Figure 3). The different contributions flow from the axis "training" + "municipal intervention" in tourism, in line with Hardy's [16] approaches, and conclude with a certain vision of "the situation", which is, in the opinion of the majority, "regular". Figure 3 shows the most significant literal expressions; those that best summarize the opinion of the group as a whole.

The "relationship tree" shows the links that we discovered between the questions posed by the moderators in the propositions we formulated in Table 2 and the responses obtained. This initial phase, for all the focus groups, makes it possible to observe the structure of the links between the different issues under discussion. Figure 4 shows the sequencing of the factors that generate what we can describe as the "tourism situation" (Proposition 1). The aim is to answer the question: What is the order of factors that define the tourism situation in Extremadura? To do this, we start with the following descriptors, which, in essence, order and hierarchize the propositions and codes generated in the project. 


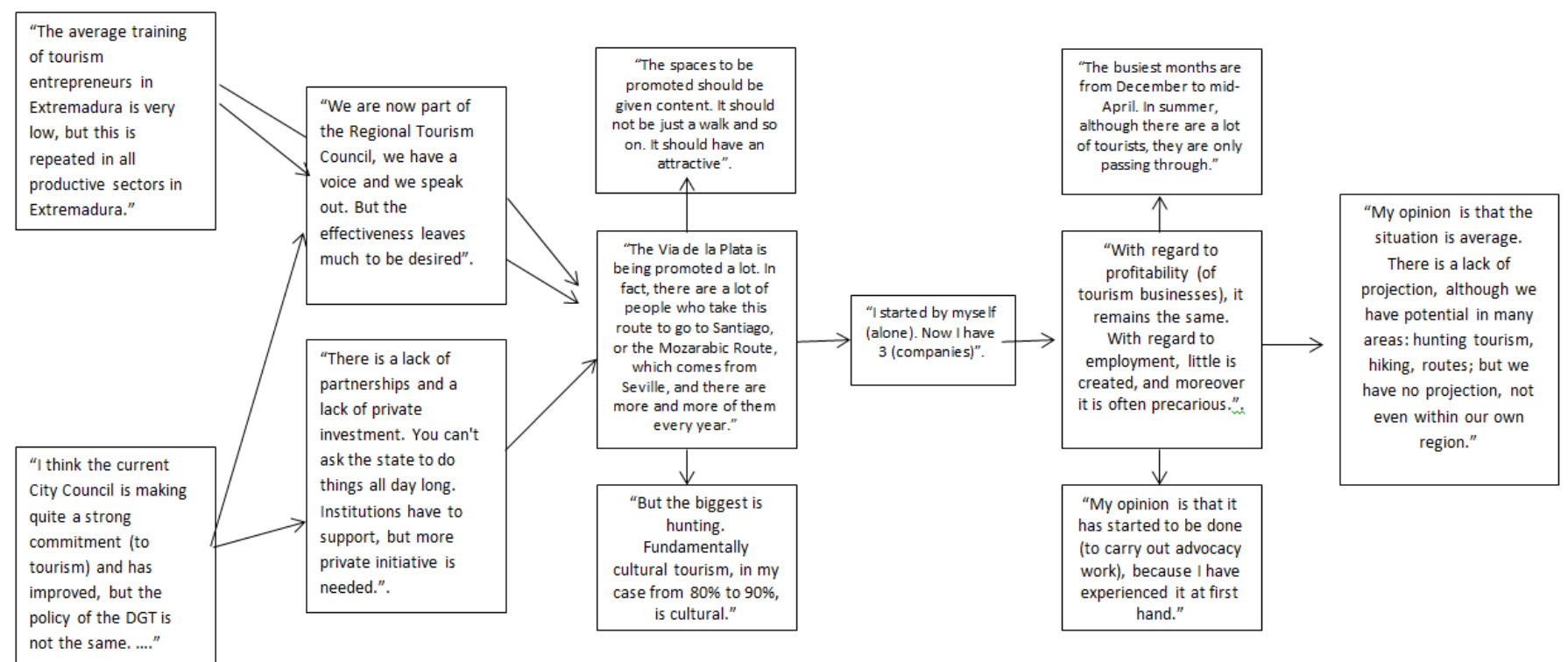

Figure 3. Relationship tree for the set of contributions from the focus groups in Extremadura. Source: own elaboration.

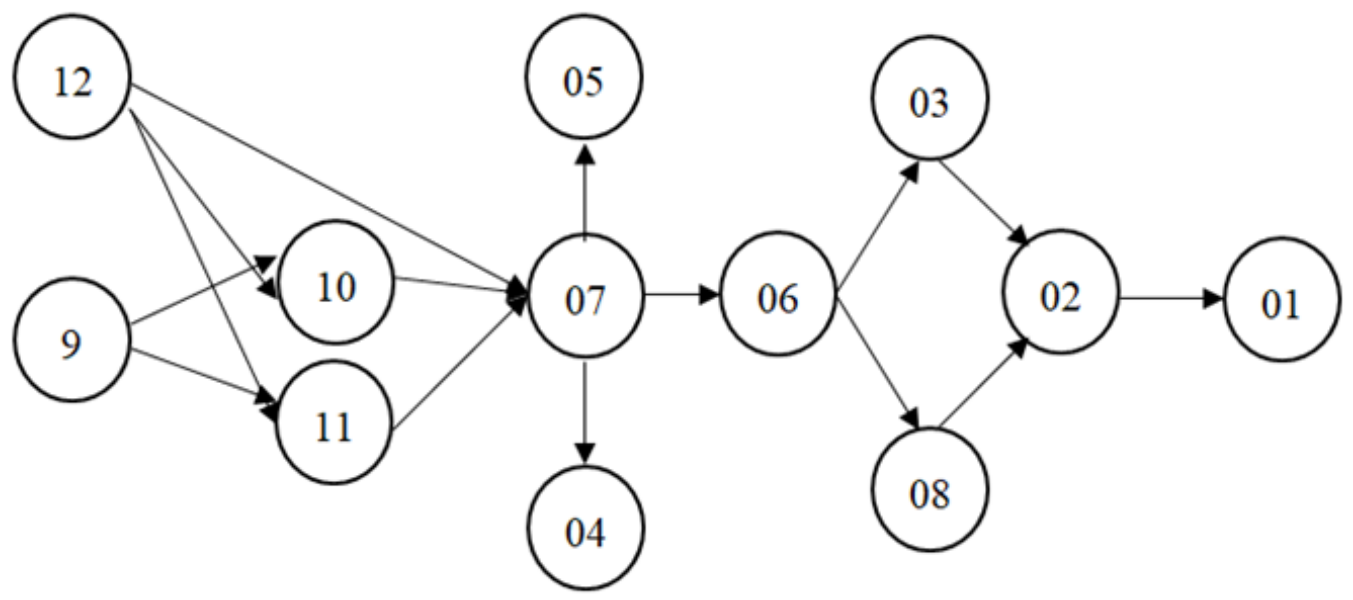

Figure 4. Sequencing of tourist elements to develop tourism in Extremadura. Source: own elaboration based on speech processing with ATLAS.ti software.

In general terms, and by way of an explanation of Figure 4 and Table 6, all the issues discussed in the six focus groups seem to have in common a demand, sometimes more explicit and sometimes latent: the need to increase the training of tourism professionals (12, Proposition 8, in accordance with the proposals of Wilson, Fesenmaier, Fesenm, and Van Es [51]), with a triple purpose:

a. Firstly, to move from being agents who inform public policies to agents who "contribute" to these policies; that is, to take a step further in their involvement as part of the human team that designs public policies (10, Proposition 6, in accordance with Buhalis and Michopoulou [55]) and the promotion of tourism in the region (11, Proposition 7, according to González-Herrera and Álvarez-Hernández [52] and to Buhalis and Michopoulou [55]).

b. Promote a shift that reinforces the coordination of tourism policies (in which, in addition to the Regional Government, provincial governments and municipalities are competent) (09, Proposition 6). This "shift" also implies involving the private sector in the design of public policies (10, Proposition 6), and in tourism promotion (11, Proposition 7). 
c. Both the training of tourism professionals (12, Proposition 8) and the active role of the private sector (10; 11, Proposition 6 and 7), and the correct design of public policies by the regional administration, in the opinion of the focus group members, should contribute decisively to obtaining the necessary return on investment (07, Proposition 2 and 3, in line with Wilson, Fesenmaier, Fesenm, and Van Es [51], with Lindroth, Ritalahti, and Soisalon [21], and with Aichholzer [58]) in tourism activities in Extremadura.

Table 6. Figure 4 codes interpretation.

\begin{tabular}{cc}
\hline Figure 4 Code & Meaning \\
\hline 01 & Improvement of the situation of tourism in Extremadura \\
\hline 02 & Improvement in profitability and employment in the region \\
\hline 03 & Increase in reservations and sales \\
\hline 04 & Types of tourism \\
\hline 05 & Tourism that is considered to have a low impact or which has the potential for a greater impulse \\
\hline 06 & Return on investment to the private sector \\
\hline 08 & Increase in the average rate of overnight stays \\
\hline 09 & Coordination of tourism policies (in which, in addition to the Regional Government, provincial \\
governments and municipalities are competent)
\end{tabular}

Source: own elaboration.

In principle, it can be interpreted that the characteristics of each area will have an effect on the types of tourism (04, Proposition 4, according to Strielkowski, Riganti, and Wang [15] and to Jacobsen [11]), especially with tourism that is considered to have a low impact (05, Proposition 8) or which has the potential for a greater impulse, depending on the area in question.

This return on investment to the private sector makes the tourism industry a businesscreating sector (06, Proposition 82), whose immediate effects will be an increase in reservations and sales (03) and an increase in the average rate of overnight stays (08; Proposition $5)$ in the region.

This relational approach allows us to discover that both factors, in the opinion of the participants in the focus groups, are those that will best contribute to the improvement in profitability and employment in the region (02, Proposition 1 ) and, finally, to the improvement of the situation of tourism in Extremadura (01, Proposition 1).

As can be seen in the diagram (Figure 4 and Table 6), training (12, Proposition 8) is considered an essential element in the process of building a sustainable tourism system. If we analyze the importance given to the training factor by the different discussion groups (see Table 5), it has an important weight within the sector. If not the main factor, it is a second group of concerns. For example, in the Plasencia focus group, it occupied first place among the concerns of the participants, together with economic profitability and tourism promotion.

\section{Discussion}

The results of this research are noteworthy, because the analysis of the different stakeholders' opinions reveals that they emphasize the training of human capital in the tourism sector. The tourism activity has relatively little added value in the economic system of a region similar to that studied, where the primary sector is still very relevant, which 
means that the participants in the groups tend to consider that increasing the value of tourism products involves giving priority to the quality of training. In works such as that of Hughes [56], which studies the factors that affect the satisfaction of the tourist experience, the training of the guides is pointed out; but it is quality that makes a greater perception of similarity between the values, expectations, and experiences of the tourists and their guide possible. Let us say that the guide must "measure up" to the group, as a necessary condition. Training, here, is a factor, not a condition for the sustainability of the business, as occurs in what we discovered in our work in Extremadura.

Behringer, Buerki and Fuhrer [54] are more in line with our findings. The discussion groups emphasize training as a necessary condition for the challenge of reconversion of the tourism sector in the face of changes in demand resulting from the effects of climate change. Here, training is conceived as a source of innovation, which should contribute to tourism management strategies in the mountainous regions of the Alps, which are heavily affected by global warming and melting ice. Additionally, in this line, we have to point out the research of Wilson, Fesenmaier, Fesenm, and Van Es [51], who studied the factors that help rural communities to successfully develop tourism and its entrepreneurial opportunities, based on several focus groups with entrepreneurs and local leaders in Illinois. Again, human capital formation allows for the adaptation of resources and the implementation of a rural tourism offer adapted to the demands of a given location and the maintenance of environments in a sustainable manner.

In any case, training as an implicit demand of the tourism sector must be included among the social effects that the development of this sector has on the receiving regions, especially when they are eminently rural and relatively undeveloped, as is the case of Extremadura. These effects, already highlighted by Ruiz Olabuénaga [61] in the 1990s, apply, in our opinion, to the changes that tourism generates in Extremadura and the sequence that makes it necessary to train human capital to meet the new demands. The most visible changes are in the social structure of the population, especially in the professional structure, the income structure, the occupational level, and in the remodeling of the social classes. The opening of new hotels, the boom in commerce, transport, and services led to the development of new occupations and professions and with it an increase in the income of the members of the host society. At the same time, the increase in the income levels of the population favors the development of the educational system, which has to attend to the training of new professionals and boost their levels of consumption, encouraged by the new levels of purchasing power, as well as by the new social aspirations to imitate the lifestyles of the affluent visitors [62].

Training, as a key factor for improving tourism supply, should consider other factors that, in addition to the quality of the tourism service itself, also affect consumer perception and behavior. Some of these factors have been highlighted by classic studies, such as those of John Urry [63], and by more recent ones, such as those of Light [64]. Light explains how visitor empathy is an important factor in improving customer response, so that the training of professionals in the sector should also have an impact on improving this factor.

On the other hand, it is evident that tourism professionals should also bear in mind the emergence of new typologies or variants within tourism that do not seek only sun and beach, such as, for example, educational or training tourism or mass tourism, derived from the idiosyncrasies of the new tourist destinations that are emerging $[64,65]$. The agents of the sector, especially in rural regions such as Extremadura, should be aware of the relations with nearby urban environments. Tourism mobility [66] of medium distance, since short-radius trips, of one day or one weekend duration, represents most of the tourist activity that takes place in rural inland tourist regions, such as Extremadura.

Finally, a factor that is hardly considered in the training of tourism professionals is the geopolitical changes occurring in nearby international environments, such as the changes in political regimes in North Africa or in Central and Eastern Europe (CEE) [64,65], which have only recently enjoyed democratic political systems. This turns these countries into alternative destinations that, as they are perceived as safer, attract more tourists, 
due to their greater economic competitiveness, their novelty, and their picturesque characteristics (language, culture, landscapes, and traditions very different from the more consolidated destinations).

\section{Conclusions}

The analysis of the discourse of the six focus groups led to a series of conclusions that, in general, are congruent with other sources of data, such as the standardized surveys of businesspeople and the semi-directive interviews that we conducted with an important group of socio-economic actors in the sector. These conclusions point to the fact that, of all the problems under discussion, and, therefore, of concern among stakeholders, three major groups can be classified according to the volume of data generated about them.

The first joint discussion axis was the "evaluation of the sector considering returns and promotion", which refers to the situation of the tourism sector in the area/region, and the return on investment and tourism promotion. Together these thematic axes occupy a third of the content of all the debates. The groups focused a large part of their contributions on analyzing the situation of the sector, and many of the contributions were critical, with proposals for improvement; but others were centered on assessing the progress to date (from before the coronavirus health crisis). The problem of tourist promotion is something that worries most of the localities, although in places similar to Cáceres and Guadalupe, there was less insistence on this. Additionally, the problem of the delay of investments has been very present in the debates of Badajoz, Mérida and Guadalupe.

The second joint discussion axis involved "training for tourism take-off", the profitability of the business, established in sales, bookings, prices, and overnight stays, in the training of human capital. These are the thematic axes that have a secondary weight in the debates, but which are transversal to all the groups. From our point of view, there is a link between all these aspects, which has been highlighted in the analysis of Figures 3 and 4 . Training is probably the necessary condition for generating complementary offers and reinforcing the quality of tourist services, which in turn will contribute to increasing overnight stays in Extremadura and ensuring the profitability of businesses.

The third axis of discussion offers a great dispersion of aspects, only linked together because they were found to be the least important in the discussions of the focus groups as a whole. In this category we include the topic of business creation. The issue of tourism entrepreneurship does not seem to be a major concern among stakeholders. Another axis of discussion that occupied the debate, but with little intensity, was the role of social actors in the articulation of the sector; in Cáceres, this is the most relevant (9.7\%). In general, the promotion of types of tourism that are not well exploited, or the search for new segments, was of less interest to all the groups.

One of the limitations of this work is the lack of participation in the focus groups of a significant percentage of the "key informants" selected and invited. Thus, for example, it can be seen that 84 people were invited to participate in these dynamics (Table 2), while 38 people actually attended the focus groups, that is, only $45.2 \%$ of those invited. This deviation introduces biases in the representation in the groups of some important sectors of the interest groups, specifically the one referring to the private initiative sector (urban entrepreneur and tourism business association), which causes systematic errors in the coverage of the initial sample.

In spite of this, we consider this work to be an interesting contribution to research on tourism planning and management in rural areas characterized by low population densities, highlighting the importance of taking into consideration the contributions, opinions, and know-how of the social and economic agents involved in the tourism sector as a key element of analysis.

Author Contributions: Conceptualization, M.S.-O.S. and J.C.-S.; methodology, M.S.-O.S. and R.R.R.; software, M.S.-O.S. and R.R.-R.; validation, M.S.-O.S. and R.R.-R.; formal analysis, M.S.-O.S.; investigation, M.S.-O.S.; resources, M.S.-O.S. and R.R.-R.; data curation, M.S.-O.S.; writing-original draft preparation, M.S.-O.S. and J.C.-S.; writing—review and editing, all authors; visualization, M.S.- 
O.S. and J.C.-S.; supervision, R.R.-R.; project administration, J.C.-S.; funding acquisition, M.S.-O.S. and J.C.-S. All authors have read and agreed to the published version of the manuscript.

Funding: The publication of this work was possible thanks to the funding provided by the European Regional Development Fund and by the Consejería de Economía, Ciencia y Agenda Digital from Junta de Extremadura through grant GR18052.

Data Availability Statement: The data that support the findings of this study are available from the corresponding author, upon reasonable request.

Acknowledgments: The research resulting in this publication was made possible thanks to the interadministrative collaboration agreement signed between the Directorate General of Tourism and the University of Extremadura for the study of tourism in the region during 2018. We would, therefore, like to thank Francisco Martin Simón, Director General of Tourism of the Junta de Extremadura (Spain), for the trust he has placed in our team. We would also like to thank the researchers María de la Cruz Sánchez Escobedo, Héctor Valentín Jiménez Naranjo, and Rocío Blanco Gregory for their collaboration and commitment to the development of the focus groups in Extremadura (Spain), as well as the research assistants Gema Cárdenas Alonso and Jennifer González.

Conflicts of Interest: The authors declare no conflict of interest.

\section{References}

1. Ortí, A. La apertura y el enfoque cualitativo o estructural: La entrevista abierta semidirectiva y la discusión de grupo. In El Análisis de la Realidad Social. Métodos y Técnicas de Investigación; Alianza Editorial: Madrid, Spain, 1986; Volume 176.

2. Fiske, M.; Kendall, P.L.; Merton, R. The Focused Interview. A Manual of Problems and Procedures; Free Press: Glencoe, IL, USA, 1956.

3. Giner, S.; Emilio-Torres, C. Diccionario de Sociología Alianza; Editorial SA: Madrid, Spain, 1998.

4. Gibbs, A. Focus groups. Soc. Res. Update 1997, 19, 1-8.

5. Grudens-Schuck, N.; Allen, B.L.; Larson, K. Focus Group Fundamentals: Methodology Brief; Iowa State University Extension PM: Ames, IA, USA, 2004.

6. Weeden, C. A qualitative approach to the ethical consumer: The use of focus groups for cognitive consumer research in tourism. In Tourism Research Methods: Integrating Theory with Practice; CABI: Wallingford, UK, 2005; pp. 179-190.

7. Gutiérrez Brito, J. La Investigación Social del Turismo; Thomson: Madrid, Spain, 2007.

8. Taylor, S.J.; Bogdan, R. Introducción a los Métodos Cualitativos de Investigación; Ediciones Paidós: Barcelona, Spain, $1987 ;$ Volume 1.

9. Riley, R.W.; Love, L.L. The state of qualitative tourism research. Ann. Tour. Res. 2000, 27, 164-187. [CrossRef]

10. Northcote, J.; Macbeth, J. Conceptualizing yield: Sustainable tourism management. Ann. Tourism Res. 2006, 33, 199-220. [CrossRef]

11. Jacobsen, J.K.S. Anti-tourist attitudes: Mediterranean charter tourism. Ann. Tour. Res. 2000, 27, 284-300. [CrossRef]

12. Ibañez, J. Cómo se realiza una investigación mediante grupos de discusión, en. In El Análisis de la Realidad Social. Métodos y Técnicas de Investigación; Alianza Editorial: Madrid, Spain, 2010; pp. 57-98.

13. Qiu, H.Z.; Yuan, J.J.; Ye, B.H.; Hung, K. Wine tourism phenomena in China: An emerging market. Int. J. Contemp. Hosp. Manag. 2013, 25, 1115-1134.

14. Dwyer, L.; Mellor, R.; Livaic, Z.; Edwards, D.; Kim, C. Attributes of destination competitiveness: A factor analysis. Tour. Anal. 2004, 9, 91-101. [CrossRef]

15. Strielkowski, W.; Riganti, P.; Jing, W. Tourism, cultural heritage and e-services: Using focus groups to assess consumer preferences. Tourismos 2012, 7, 41-60.

16. Hardy, A. Using grounded theory to explore stakeholder perceptions of tourism. J. Tour. Cult. Chang. 2005, 3, 108-133. [CrossRef]

17. Guba, E.G. The paradigm dialog. In Proceedings of the Alternative Paradigms Conference, San Francisco, CA, USA, March 1989.

18. Neuman, W.L.; Kreuger, L. Social Work Research Methods: Qualitative and Quantitative Approaches; Allyn and Bacon: Boston, MA, USA, 2003.

19. Guba, E.G.; Lincoln, Y.S. Fourth Generation Evaluation; Sage: Thousand Oaks, CA, USA, 1989.

20. Bristol, T.; Fern, E.F. Exploring the atmosphere created by focus group interviews: Comparing consumers' feelings across qualitative techniques. Market Res. Soc. J. 1996, 38, 1-9. [CrossRef]

21. Lindroth, K.; Ritalahti, J.; Soisalon-Soininen, T. Creative tourism in destination development. Tour. Rev. 2007, 62, 53-58. [CrossRef]

22. Polkinghorne, D.E. Phenomenological research methods. In Existential-Phenomenological Perspectives in Psychology; Springer: Berlin/Heidelberg, Germany, 1989; pp. 41-60.

23. Patton, M.Q. Qualitative Research E Evaluation Methods: Integrating Theory and Practice; Sage Publications: Thousand Oaks, CA, USA, 2014.

24. Hu, C.-P.; Chang, Y.-Y.; John, W. Creswell, Research Design: Qualitative, Quantitative, and Mixed Methods Approaches; Sage Publications: Thousand Oaks, CA, USA, 2017; Volume 4, p. 3. [CrossRef]

25. Sánchez-Hernández, M.I.; Robina-Ramírez, R.; De Clercq, W. Water Management Reporting in the Agro-Food Sector in South Africa. Water 2017, 9, 830. [CrossRef] 
26. Bernard, H.R.; Wutich, A.; Ryan, G.W. Analyzing Qualitative Data: Systematic Approaches; SAGE Publications: Thousand Oaks, CA, USA, 2016.

27. Sánchez-Oro Sánchez, M.; Robina Ramírez, R. Los Grupos Focales ("focus group") Como Herramienta de Investigación Turística; Universidad de Extremadura, Servicio de Publicaciones: Badajoz, Spain, 2020.

28. Pearce, P.L.; Gretzel, U. Tourism in technology dead zones: Documenting experiential dimensions. Int. J. Tour. Sci. 2012, 12, 1-20. [CrossRef]

29. Rossiter, J. Measurement for the Social Sciences-The C-OAR-SE Method and Why It Must Replace Psychometrics; Springer: New York, NY, USA, 2011.

30. Gomm, R. Social Research Methodology: A Critical Introduction; Palgrave Macmillan: London, UK, 2008.

31. Cleland, J. The Wisdom of Whores. E Pisani; Oxford University Press: Oxford, UK, 2008.

32. Flick, U. An Introduction to Qualitative Research; SAGE Publications: Thousand Oaks, CA, USA, 2006.

33. Jennings, G. Tourism Research, 2nd ed.; Wiley Milton Qld: Milton, QLD, Australia, 2010.

34. Krueger, R.a.M.C. Focus Groups-A Practical Guide for Applied Research; Sage Publications Inc.: London, UK, 2000.

35. Angen, M.J. Evaluating Interpretive Inquiry: Reviewing the Validity Debate and Opening the Dialogue. Qual. Health Res. 2000, 10, 378-395. [CrossRef] [PubMed]

36. Decrop, A. Triangulation in qualitative tourism research. Tour. Manag. 1999, 20, 157-161. [CrossRef]

37. Denzin, N.K.; Lincoln, Y.S. The SAGE Handbook of Qualitative Research; SAGE Publications: Thousand Oaks, CA, USA, 2011.

38. Tribe, J. New Tourism Research; Taylor \& Francis: Milton Park, UK, 2005.

39. Botterill, D. An Autoethnographic Narrative on Tourism Research Epistemologies. Soc. Leis. 2003, 26, 97-110. [CrossRef]

40. Hardy, A.; Beeton, R.J. Sustainable tourism or maintainable tourism: Managing resources for more than average outcomes. J. Sustain. Tour. 2001, 9, 168-192. [CrossRef]

41. Gunn, C.A. Emergence of effective tourism planning and development. In Tourism: The State of the Art; Wiley: Hoboken, NJ, USA, 1994; pp. 10-19.

42. Cole, S. Information and Empowerment: The Keys to Achieving Sustainable Tourism. J. Sustain. Tour. 2006, 14, 629-644. [CrossRef]

43. Carter, S. Tourists' and travellers' social construction of Africa and Asia as risky locations. Tour. Manag. 1998, 19, 349-358. [CrossRef]

44. Glaser, B.G.; Strauss, A.L. Discovery of Grounded Theory: Strategies for Qualitative Research; Taylor \& Francis: Milton Park, UK, 2017.

45. Morgan, D.L. Qualitative Research Methods: Focus Groups as Qualitative Research; SAGE Publications: Thousand Oaks, CA, USA, 1997; Volume 10, p. 9781412984287.

46. Krueger, R.A. Focus Groups: A Practical Guide for Applied Research; Sage Publications: Thousand Oaks, CA, USA, 2014.

47. Byrd Erick, T. Stakeholders in sustainable tourism development and their roles: Applying stakeholder theory to sustainable tourism development. Tour. Rev. 2007, 62, 6-13. [CrossRef]

48. Osorio, F. Estudio Anual de la Evolución de los Principales Indicadores Turísticos de Extremadura en 2018; Dirección General de Turismo, Junta de Extremadura: Mérida, Mexico, 2019; p. 35.

49. Sánchez-Oro Sánchez, M.; Nieto Masot, A.; Fernandez Portillo, A.; García García, Y.; Cárdenas Alonso, G. Memoria Turística de Extremadura por Territorios. Perfíl del Turista que Visita Extremadura año 2018; Dirección General de Turismo de la Junta de Extremadura: Mérida, Mexico, 2019.

50. King, G.; Keohane, R.; Verba, S. Causalidad e inferencia causal. In El Diseño de la Investigación Social: La Inferencia Científica en los Estudios Cualitativos; Alianza: Madrid, Spain, 2000.

51. Wilson, S.; Fesenmaier, D.R.; Fesenmaier, J.; Van Es, J.C. Factors for success in rural tourism development. J. Travel Res. 2001, 40, 132-138. [CrossRef]

52. González-Herrera, M.; Alvarez-Hernández, J.A. Diagnóstico participativo del turismo en Ciudad Juárez desde las voces de los actores locales. Rev. Iberoameric. Cienc. 2014, 1, 117-134.

53. Martinez Quintana, V.; Blanco Gregory, R. Naturaleza y Urbes en el Ocio y el Turismo. Perspectiva Sociológica en la Planificación de los Hábitats de Recreación; Académicas, E., Ed.; Ediciones Académicas: Madrid, Spain, 2011.

54. Behringer, J.; Buerki, R.; Fuhrer, J. Participatory integrated assessment of adaptation to climate change in Alpine tourism and mountain agriculture. Integr. Assess. 2000, 1, 331-338. [CrossRef]

55. Buhalis, D.; Michopoulou, E. Information-enabled tourism destination marketing: Addressing the accessibility market. Curr. Issues Tour. 2011, 14, 145-168. [CrossRef]

56. Hughes, K. Tourist satisfaction: A guided "cultural" tour in North Queensland. Austr. Psychol. 1991, 26, 166-171. [CrossRef]

57. Santana Leitner, A. Fundamentos Para la Investigación Social; Alianza Editorial: Madrid, Spain, 2013.

58. Westholm, H.; Aichholzer, G. Prisma Strategic Guideline; Prisma Project; 2003. Available online: Prisma-EU.net (accessed on 10 April 2021).

59. Taylor, A.; Prideaux, B. Profiling four wheel drive tourism markets for desert Australia. J. Vac. Mark. 2008, 14, 71-86. [CrossRef]

60. Hall, C.M.; Valentin, A. Content Analysis. In Tourism Research Methods. Integrating Theory with Practice; CABI Publishing: Wallingford, UK, 2004; pp. 191-210.

61. Foessa, F. Informe Sociológico Sobre la Situación Social de España; Euramérica: Madrid, Spain, 1994. 
62. Sánchez-Oro Sánchez, M. Aproximación socilogica al turismo en Extremadura. In Recursos Turísticos, Territorio y Sociedad en Extremadura: Catalogación, Nuevos Usos y Perspectivas; Servicio de Publicaciones de la Universidad de Extremadura: Cáceres, Spain, 2021.

63. Urry, J.; Larsen, J. The Tourist Gaze 3.0; Sage: Thousand Oaks, CA, USA, 2011.

64. Light, D.; Creţan, R.; Voiculescu, S.; Jucu, I.S. Introduction: Changing Tourism in the Cities of Post-communist Central and East. Europe. J. Balkan Near Eastern Stud. 2020, 22, 465-477. [CrossRef]

65. Adams, K.; Crang, M.; Edensor, T.; Flusty, S.; Jacobs, J.; Raento, P.; Urry, J.; Veijola, S.; Wang, N. Travels in Paradox: Remapping Tourism; Rowman \& Littlefield Publishers: Lanham, MD, USA, 2006.

66. Sheller, M.; Urry, J. Tourism Mobilities: Places to Play, Places in Play; Routledge: London, UK, 2004. 